\title{
EVALUASI PENGEMBANGAN KURIKULUM MUATAN LOKAL SEKOLAH DASAR NEGERI KOTA MEULABOH
}

\author{
Tengku Hafinda \\ Sekolah Tinggi Agama Islam Negeri Teungku Dirundeng Meulaboh \\ Email: tengkuhafinda@staindirundeng.ac.id
}

\begin{abstract}
Abstrak
Penelitian ini dilatarbelakangi oleh masih belum optimalnya kondisi pengembangan kurikulum muatan lokal Sekolah Dasar Negeri Kota Meulaboh. Penelitian ini bertujuan untuk melakukan evaluasi terhadap pengembangan kurikulum muatan lokal Sekolah Dasar Negeri Kota Meulaboh. Permasalahan pokok pada penelitian ini berkenaan dengan bagaimana hasil evaluasi terhadap pengembangan kurikulum muatan lokal Sekolah Dasar Negeri Kota Meulaboh. Model evaluasi yang digunakan yaitu model evaluasi kuantitatif. Evaluasi dilakukan dengan mengumpulkan informasi yang berupa data kondisi pengembangan kurikulum untuk kemudian dianalisis rata-rata persentase aspek dengan menggunakan analisis deskriptif. Instrumen yang digunakan yaitu angket, dan lembar observasi dokumen. Populasi terdiri dari enam sekolah yang menerapkan Kurikulum 2013 dan responden terdiri dari enam kepala sekolah, dan sembilan belas guru. Hasil penelitian evaluasi kurikulum muatan lokal Sekolah Dasar Negeri Kota Meulaboh menunjukkan bahwa kondisi pengembangan kurikulum berkategori baik (59\%). Simpulan hasil penelitian menunjukkan bahwa secara keseluruhan pengembangan kurikulum sudah berkategori baik hal ini dapat ditinjau dari kondisi pengembangan kurikulum dalam masing-masing aspek evaluasi berkategori baik.
\end{abstract}

Kata kunci: Evaluasi, Pengembangan Kurikulum, Dan Kurikulum Muatan Lokal.

\begin{abstract}
This research was motivated by the fact that local content curriculum development in schools, was not yet optimal. This research aimed to evaluate local content curriculum development of elementary schools in Meulaboh. The main problem of this research was how the evaluation results of the development of local curriculum in Meulaboh Elementary School. This research was evaluated study using quantitative models. Evaluation is done by collecting information in the form of data component of curriculum development to then analyzed average percentage aspect by using descriptive analysis. The instruments used were questionnaires, and document observation sheets. The population consisted of 6 schools pilotting Curriculum 2013 and respondents consisted of 6 headmasters, and 19 teschers were chosen using purposive sampling technique. The results of the research indicate that: the condition of curriculum development categorized good category $(59 \%)$. The results showed that over all components of the evaluation in the evaluation of each aspect of good category. Keywords: Evaluation, Development Implementation, And Local Content Curriculum.
\end{abstract}




\section{A. PENDAHULUAN}

Kurikulum di Indonesia terus dikembangkan seiring berjalannya waktu dengan disesuaikan pada perkembangan zaman, ilmu pengetahuan dan teknologi demi mewujudkan pendidikan yang berkualitas. Seperti halnya kurikulum 2013, pada proses penerapannya lebih menitik beratkan sikap sebagai elemen tepenting. Sehingga proses pembelajarannya yang sebelumnya dianggap monoton dibuat semenarik mungkin agar siswa dengan mudah memahami pelajaran. Dalam kurikulum 2013 ini pula tata cara pelaksanaan pembelajaran lebih difokuskan kepada menyimak, menanya, mempraktek, menalar kemudian mengkomunikasikan. Oleh karena itu, implementasi kurikulum dianggap cocok dan diharapkan dapat meningkatkan mutu pendidikan khususnya pada output yang dihasilkan oleh sekolah.

Bentuk lain dalam mewujudkan pendidikan yang berkualitas ialah menciptakan pendidikan yang berkaitan dengan unsur-unsur lokal Indonesia. Seperti yang tercantum dalam Undang-Undang Nomor 20 Tahun 2003 tentang Sistem Pendidikan Nasional Pasal 50 dinyatakan bahwa "Pemerintah Kabupaten/Kota mengelola pendidikan dasar dan pendidikan menengah, serta satuan pendidikan yang berbasis keunggulan lokal”. Berdasarkan hal tersebut diharapkan nantinya generasi muda mampu memanfaatkan segala sumber daya yang tersedia dan mampu menjadikannya sebagai suatu kekuatan bangsa Indonesia. Untuk itu pendidikan memfasilitasinya dengan adanya kurikulum muatan lokal. Sejak berlakunya Permendikbud RI No. 79 Tahun 2014 tentang Muatan Lokal Kurikulum 2013 Pasal 1 ayat (1) disebutkan bahwa "muatan lokal adalah bahan kajian atau mata pelajaran pada satuan pendidikan yang berisi muatan dan proses pembelajaran tentang potensi dan keunikan lokal.

Berdasarkan hal tersebut, kurikulum muatan lokal mengindikasikan suatu keunikan dan kekhasan setiap jenjang pendidikan dan setiap sekolah. Kurikulum muatan lokal merupakan wujud mempertahankan nilai-nilai kebudayaan dan kearifan lokal Indonesia yang tidak dapat dihilangkan walaupun perkembangan zaman yang sudah semakin pesat. Kurikulum muatan lokal dapat disusun oleh setiap jenjang pendidikan atau sekolah sesuai dengan potensi daerah yang dimiliki. Pada prinsipnya muatan lokal dikembangkan atas kesesuaian dengan perkembangan peserta didik, keutuhan kompetensi, fleksibilitas jenis, bentuk, dan pengaturan waktu penyelenggaraan dan kebermanfaatan untuk kepentingan nasional dan menghadapi tantangan global. Muatan lokal dapat berupa seni budaya, prakarya, pendidikan jasmani, olahraga, dan kesehatan, bahasa, dan/atau teknologi.

Dalam pelaksanaannya muatan lokal dalam Kurikulum 2013 pada jenjang Sekolah Dasar dapat dilakukan dengan dua cara, yaitu dengan cara mengintergrasikan muatan lokal tersebut dalam suatu tema atau dengan cara menyusun satu tema muatan lokal yang berdiri sendiri dengan menambah beban belajar muatan lokal paling banyak 2 (dua) jam per minggu.

Berkaitan dengan kurikulum muatan lokal, beberapa hasil penelitian yang sudah dilakukan sebelumnya antara lain berdasarkan hasil penelitian Nasir (2013) menunjukkan bahwa:

... Persoalan dalam implementasi kurikulum muatan lokal sampai saat ini cukup pelik. Hal ini berkaitan perencanaannya, pelaksanaan dan evaluasinya. Dilihat dan segi ketenagaan, pelaksanaan muatan lokal memerlukan pengorganisasian secara khusus karena melibatkan pihak-pihak lain selain sekolah. Dilihat dan segi proses belajar mengajar, pelaksanaan muatan lokal dapat menggunakan pendekatan keterampilan proses dan pendekatan kontekstual. 
Selain itu hasil penelitian yang dilakukan oleh Kamwendo dan Seretse (2014) pada sekolah di Botswana menunjukkan bahwa tingkat penyertaan keberagaman bahasa di dalam kurikulum sekolah belum dapat dikatakan baik. Hal ini ditemukan dalam kurikulum yang hanya memberikan pengakuan pada satu bahasa lokal saja dan menggunakan bahasa Inggris dalam bahasa yang wajib digunakan selama pembelajaran di sekolah. Berdasarkan penelitian ini juga memunculkan klaim bahwa kurikulum sekolah mengakibatkan budaya dan bahasa lokal tidak terlihat. Penelitian ini mengungkapkan bahwa kurikulum sekolah di Botswana lebih memberikan akomodasi terhadap kurikulum pendidikan agama daripada kurikulum bahasa.

Kurikulum muatan lokal untuk daerah Aceh telah ditetapkan dalam Qanun Aceh Nomor 11 Tahun 2014 Pasal 44 Tentang Penyelenggaraan Pendidikan bahwa bahasa Aceh merupakan salah satu muatan lokal yang dapat digunakan dalam setiap jenjang pendidikan formal. Selain bahasa Aceh, untuk Sekolah Dasar Kota Meulaboh juga ada tulisan Arab Indonesia, Bahasa Inggris dan TIK. Tujuan muatan lokal secara umum adalah untuk mempersiapkan peserta didik agar memiliki wawasan yang luas dan mantap tentang keadaan lingkungan dan kebutuhan masyarakat sesuai dengan nilai dan aturan yang berlaku di daerahnya dan mendukung kelangsungan pembangunan daerah serta pembangunan nasional.

Namun saat ini kebijakan tersebut belum membuahkan hasil yang signifikan dalam meningkatkan kualitas sosial dan budaya daerah, hal ini terlihat dari fenomena yang belakangan ini sering terjadi, yaitu ketika penggunaan bahasa daerah dikalangan generasi muda sudah menurun dan lebih menyukai menggunakan bahasa asing ataupun bahasa lain yang dianggap lebih modern. Fenomena tersebut bermunculan dimanapun keberadaan generasi muda yang menunjukkan gejala bahwa mereka seakan malu dengan bahasa daerahnya walaupun di sekolah terdapat muatan lokal yang mempelajari kearifan dan budaya lokal. Berdasarkan fenomena tersebut muncul suatu indikasi bahwasannya ada yang salah dalam sistem pendidikan yang telah ataupun sedang ditempuhnya. Kurikulum muatan lokal menjadi dipertanyakan dimana posisinya dalam menciptakan generasi muda yang canggih namun juga tetap memegang teguh adat, budaya dan agamanya. Dalam struktur Kurikulum 2013 memang muncul mata pelajaran muatan lokal yang ditumpangkan pada mata pelajaran tertentu yang alokasi waktunya tergolong sangat minim. Hal ini memberi gambaran betapa sulitnya mata pelajaran muatan lokal memeperoleh alokasi waktu (Suyitno, 2014).

Berdasarkan pemikiran tersebut, penulis ingin mengkaji dan menganalisis bagaimana kondisi pengembangan kurikulum muatan lokal di Sekolah Dasar Negeri Kota Meulaboh. melalui kajian tersebut, diharapkan dapat memberikan gambaran tentang kondisi pengembangan kurikulum muatan lokal Sekolah Dasar Negeri Kota Meulaboh, selain itu diharapkan dapat memberikan sumbangan pada pengembangan ilmu kurikulum dan pembelajaran pendidikan dasar melalui rumusan prinsip atau kaidah-kaidah tentang ide, dokumen, implementasi, dan hasil dari sebuah kurikulum. Selanjutnya diharapkan dapat menjadi model pengembangan kurikulum muatan lokal pada jenjang Sekolah Dasar.

\section{B. METODE PENELITIAN}

\section{Jenis Penelitian}

Jenis penelitian yang digunakan ialah penelitian evaluasi. Pendekatan yang digunakan dalam penelitian ini adalah model kuantitatif dengan paradigma positivistik. Berdasarkan 
paradigma positivistik ini maka pendekatan yang dipakai dalam proses pengumpulan datanya adalah pendekatan kuantitatif dengan tradisi psikometrik. Tradisi psikometrik menurut Hasan (2009) menekankan pada penggunaan prosedur dan alat evaluasi berdasarkan prosedur yang dikenal dalam pengukuran dan metode positivistik.

Metode yang digunakan dalam penelitian ini adalah metode kuantitatif non-eksperimen, didasarkan pada apa yang dikemukakan oleh Hasan (2009) bahwa evaluasi harus berkaitan dengan kegiatan kurikulum yang terjadi dalam kenyataan. Dengan menggunakan metode noneksperiment, untuk mendapatkan data peneliti hanya merekam keadaan yang telah ada atau sedang terjadi, dan tidak memunculkan data secara sengaja atau dengan kata lain menimbulkan data baru (Arikunto, 2010).

\section{Populasi dan Sampel}

Populasi adalah wilayah generalisasi yang terdiri atas objek atau subjek yang mempunyai kualitas dan karakteristik tertentu yang ditetapkan oleh peneliti untuk dipelajari dan kemudian ditarik kesimpulannya (Sugiyono, 2013). Populasi dalam penelitian ini adalah jumlah seluruh guru muatan lokal dan kepala sekolah Sekolah Dasar Negeri Kota Meulaboh. Populasi berjumlah 19 orang guru muatan lokal, dan 6 orang kepala sekolah yang tersebar di 6 Sekolah Dasar di Kota Meulaboh yang telah menggunakan Kurikulum 2013.

Sugiyono (2013) mendefinisikan sampel sebagai bagian dari jumlah dan karakteristik yang dimiliki oleh populasi. Untuk memperoleh jumlah yang representatif, Arikunto (2010) memberikan petunjuk bahwa apabila subjek kurang dari 100 lebih baik diambil seluruhnya sehingga penelitian merupakan penelitian populasi. Penentuan sampel dalam penelitian ini dilakukan menggunakan teknik sampling jenuh dengan menggunakan semua anggota populasi sebagai sampel. Sampel dalam penelitian ini adalah guru muatan lokal, dan kepala sekolah pada Sekolah Dasar Negeri yang ada di Kota Meulaboh.

Tabel 1. Jumlah Responden Berdasarkan Status Dan Asal Sekolah

\begin{tabular}{|c|c|c|c|c|c|}
\hline \multirow[b]{2}{*}{ No } & \multirow[b]{2}{*}{ Nama Sekolah } & \multicolumn{4}{|c|}{ Status } \\
\hline & & $\begin{array}{l}\text { Kepala } \\
\text { sekolah }\end{array}$ & Guru & Jumlah & $\begin{array}{c}\text { Persentase } \\
(\%)\end{array}$ \\
\hline 1 & SD N 01 Meulaboh & 1 & 4 & 5 & 17.65 \\
\hline 2 & SD N 02 Meulaboh & 1 & 3 & 4 & 16.47 \\
\hline 3 & SD N 03 Meulaboh & 1 & 3 & 4 & 16.47 \\
\hline 4 & SD N 12 Meulaboh & 1 & 3 & 4 & 16.47 \\
\hline 5 & SD N 14 Meulaboh & 1 & 3 & 4 & 16.47 \\
\hline 6 & SD N 27 Meulaboh & 1 & 3 & 4 & 16.47 \\
\hline & Jumlah & 6 & 19 & 25 & 100.00 \\
\hline
\end{tabular}

\section{Instrumen dan Teknik Pengumpulan Data}

Teknik pengumpulan data merupakan suatu proses pengadaan data untuk kepentingan penelitian. Data yang telah terkumpul digunakan untuk menguji hipotesis yang telah dirumuskan. Teknik pengumpulan data yang digunakan peneliti adalah sebagai berikut: 


\section{a. Observasi}

Observasi adalah pengamatan dan pencatatan secara sistematik terhadap gejala yang tampak pada objek penelitian. Observasi dilakukan dengan meninjau serta melakukan pengamatan langsung terhadap objek yang diteliti yaitu Sekolah Dasar Kota Meulaboh yang terpilih menjadi sampel penelitian.

b. Dokumentasi

Di dalam melaksanakan metode dokumentasi, peneliti meyelidiki benda-benda tertulis atau data yang terdokumen seperti dokumen kurikulum muatan lokal yang diperoleh dari dokumentasi guru muatan lokal.

c. Kuesioner

Instrumen yang digunakan dalam penelitian ini adalah kuesioner yang disusun berdasarkan variabel-variabel yang dikaji dalam penelitian ini. Alasan digunakannya kuesioner adalah karena sifatnya yang tertulis memudahkan responden memberikan keleluasaan bagi responden untuk memberi data yang diperlukan dalam penelitian ini. Selain itu juga dikarenakan data hasil penelitian akan mudah untuk dianalisis karena berupa pernyataan yang sama dalam instrumen pengumpulan datanya.

Tabel 2. Kisi Instrumen Penelitian

\begin{tabular}{|c|l|l|l|l|c|c|}
\hline No & \multicolumn{1}{|c|}{$\begin{array}{c}\text { Pertanyaan } \\
\text { Penelitian }\end{array}$} & $\begin{array}{c}\text { Aspek } \\
\text { Evaluasi } \\
\text { instrumen }\end{array}$ & $\begin{array}{c}\text { Jenis } \\
\text { Penelitian }\end{array}$ & $\begin{array}{c}\text { Jumlah } \\
\text { instru } \\
\text { men }\end{array}$ & $\begin{array}{c}\text { Item } \\
\text { instru } \\
\text { men }\end{array}$ \\
\hline 1 & $\begin{array}{l}\text { Bagaimana kondisi } \\
\text { kurikulum muatan } \\
\text { lokal di Sekolah } \\
\text { Dasar Negeri Kota } \\
\text { Meulaboh? }\end{array}$ & $\begin{array}{l}\text { Dokumen } \\
\text { kurikulum } \\
\text { muatan lokal }\end{array}$ & $\begin{array}{l}\text { Kuesioner, } \\
\text { dokumenta } \\
\text { si dan } \\
\text { observasi }\end{array}$ & $\begin{array}{l}\text { Kepala } \\
\text { sekolah dan } \\
\text { guru }\end{array}$ & 15 & $1-15$ \\
\hline
\end{tabular}

\section{Teknik Analisis Data}

Setelah semua keseluruhan data terkumpul, tahap berikutnya adalah tahap analisis data atau pengolahan data. Sebelum melakukan analisis data, data hasil penelitian yang diperoleh dari lapangan dientry dan diolah terlebih dahulu. Langkah pertama yang ditempuh dalam pengolahan data diawali dengan membuat tabulasi data yang berisi frekuensi jawaban responden dari berbagai variabel yang akan disajikan. Langkah kedua yang dilakukan ialah dengan melakukan konversi data hasil penelitian dengan prosedur menjumlahkan semua skor tiap bagian instrumen dan menggunakan rumus persentase sebagai berikut:

$$
P=\frac{\text { rata }- \text { rata aktual }}{\text { rata }- \text { rata } \text { maksimal }} \times 100 \%
$$

Langkah ketiga adalah melakukan kategori data hasil penelitian dengan prosedur sebagai berikut:

a. Skor rata-rata $\mathrm{P}$ dijadikan patokan untuk membuat kriteria semua variabel yang dideskripsikan. 
b. Skor rata-rata $\mathrm{P}$ di bagi 4 (empat) kategori yang akan dijadikan kriteria dengan cara sebagai berikut:

$\mathrm{M}+(1 \mathrm{x}$ SD $)<\mathrm{P} \rightarrow$ Kategori Sangat Tinggi $(>60)$

$\mathrm{M}<\mathrm{P} \leq \mathrm{M}+(1 \times \mathrm{SD}) \rightarrow$ Kategori Tinggi (51-60)

$\mathrm{M}-(1 \mathrm{x} \mathrm{SD})<\mathrm{P} \leq \mathrm{M} \rightarrow$ Kategori Rendah (41-50)

$\mathrm{P} \leq \mathrm{M}-(1 \mathrm{x}$ SD $) \rightarrow$ Kategori Sangat Rendah $(\leq 40)$

Dengan $\mathrm{M}=50$ dan $\mathrm{SD}=10$

Tabel 3. Konversi Persentase Rata-Rata

\begin{tabular}{|c|c|}
\hline Kategori & Persentase (P) \\
\hline Tidak baik (TB) & $\mathrm{P} \leq 40$ \\
\hline Kurang baik (KB) & $41<\mathrm{P} \leq 50$ \\
\hline Baik (B) & $51<\mathrm{P} \leq 60$ \\
\hline Sangat Baik (SB) & $\mathrm{P}>61$ \\
\hline
\end{tabular}

Langkah selanjutnya adalah memberikan pertimbangan mengenai data penelitian yang diperoleh dan kemudian diteliti melalui analisis deskriptif. Dari hasil pertimbangan inilah kemudian dapat diberikan umpan balik kepada pembuat kebijakan.

\section{HASIL DAN PEMBAHASAN}

\section{Deskripsi Hasil Penelitian}

Secara umum data hasil penelitian tentang kondisi pengembangan kurikulum muatan lokal dari enam Sekolah Dasar Negeri di Kota Meulaboh yang menjadi fokus penelitian ini dapat dijabarkan sebagai berikut.

Tabel 4. Kondisi Pengembangan Kurikulum Muatan Lokal

\begin{tabular}{|c|c|c|c|c|c|c|}
\hline No & Sekolah & Tidak baik & Kurang baik & Baik & Sangat baik & Jumlah \\
\hline 1 & SDN 01 Meulaboh & $34 \%$ & $23 \%$ & $37 \%$ & $6 \%$ & $100 \%$ \\
\hline 2 & SDN 02 Meulaboh & $25 \%$ & $14 \%$ & $50 \%$ & $11 \%$ & $100 \%$ \\
\hline 3 & SDN 03 Meulaboh & $39 \%$ & $18 \%$ & $29 \%$ & $14 \%$ & $100 \%$ \\
\hline 4 & SDN 12 Meulaboh & $11 \%$ & $32 \%$ & $29 \%$ & $29 \%$ & $100 \%$ \\
\hline 5 & SDN 14 Meulaboh & $25 \%$ & $18 \%$ & $43 \%$ & $14 \%$ & $100 \%$ \\
\hline 6 & SDN 27 Meulaboh & $7 \%$ & $0 \%$ & $54 \%$ & $39 \%$ & $100 \%$ \\
\hline & Rata-rata & $24 \%$ & $18 \%$ & $40 \%$ & $19 \%$ & $100 \%$ \\
\hline
\end{tabular}


Data hasil penelitian terkait dengan kondisi pengembangan kurikulum muatan lokal terdiri dari 3 sub indikator yaitu 1) mengembangkan kurikulum muatan lokal sesuai dengan karakteristik dari peserta didik dan karakteristik daerah; 2) keterlibatan guru dalam pengembangan dan penyusunan kurikulum muatan lokal; 3) melibatkan pihak-pihak terkait dalam penyusunan dan pelaksanaan kurikulum muatan lokal. Secara umum kondisi pengembangan kurikulum muatan lokal di Sekolah Dasar Negeri Kota Meulaboh berada pada kategori baik sebesar 40\%. Kondisi pengembangan kurikulum muatan lokal di Sekolah Dasar Negeri Kota Meulaboh bervariasi di enam Sekolah yang menjadi fokus penelitian yaitu berkategori baik dengan rincian di SDN 01 Meulaboh (37\%), di SDN 02 Meulaboh (50\%), di SDN 03 Meulaboh (29\%), SDN 12 Meulaboh (29\%), SDN 14 Meulaboh (43\%) dan di SDN 27 Meulaboh (54\%). Deskripsi data kondisi pengembangan kurikulum muatan lokal dalam bentuk diagram batang sebagai berikut:

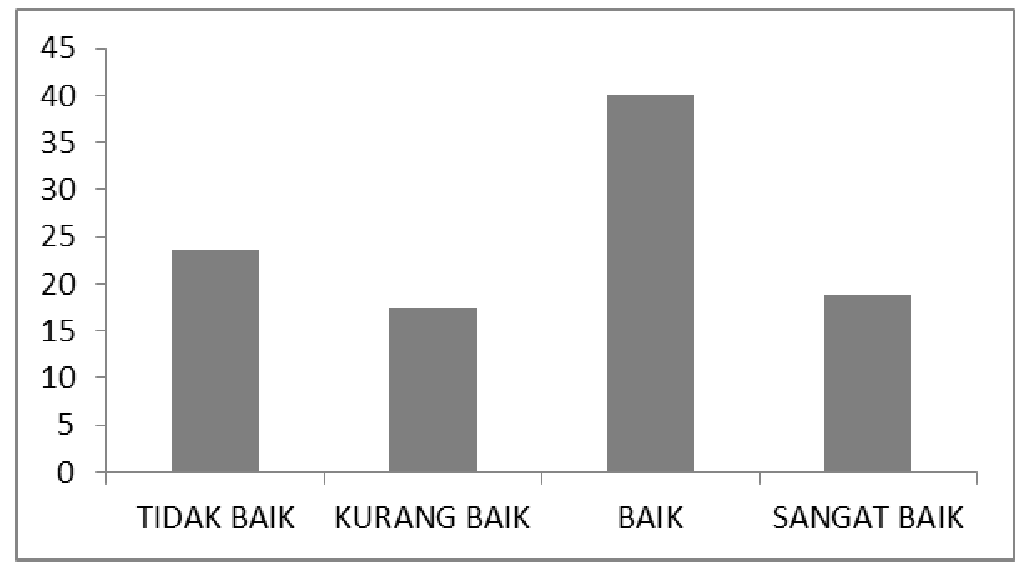

Diagram 1. Kondisi Pengembangan Kurikulum Muatan Lokal

\section{Pembahasan Hasil Penelitian}

Berdasarkan analisis data yang telah dilakukan terkait dengan kondisi pengembangan kurikulum muatan lokal diperoleh rata-rata kategori baik dan sangat baik sebesar 59\% dan ratarata tidak baik dan kurang baik sebesar $41 \%$. Pengembangan kurikulum muatan lokal yang mencakup karakteristik dan ciri khas sekolah dikembangkan dengan baik oleh sekolah. Untuk mengakomodasi kegiatan pengembangan kurikulum didukung dengan adanya tim pengembang kurikulum di setiap Sekolah Dasar Negeri Kota Meulaboh yang meliputi kepala sekolah, guru dan komite sekolah. Hal ini sesuai dengan yang dikemukakan oleh Arifin (2004) bahwa "sekolah dan komite seolah memiliki wewenang penuh dalam mengembangkan program muatan lokal". Kegiatan pengembangan kurikulum telah dikembangkan dengan baik walaupun tidak semua sekolah menganggap muatan lokal sebagai suatu hal penting yang perlu diperhatikan. Hal ini terbukti dengan ditemukannya sekolah dengan tidak adanya silabus dan RPP muatan lokal. Berdasakan temuan di lapangan diketahui bahwa pengembangan silabus biasanya sudah disusun oleh tim pengembang kurikulum yang ditunjuk atau ditugasi oleh pihak sekolah. Untuk pengembangan RPP dilakukan oleh guru yang bersangkutan sesuai dengan silabus yang telah disusun. 
Kondisi pengembangan kurikulum di Sekolah Dasar Negeri Kota Meulaboh harus didasarkan pada komitmen agar kegiatan pengembangan kurikulum yang dilakukan berusaha untuk memunculkan muatan lokal yang tepat sehingga dapat menjadikan peserta didik paham dan mampu memajukan potensi daerahnya kelak. Masuknya materi tentang muatan lokal kedalam kurikulum sekolah serta implementasinya sangat bergantung pada paradigma yang dianut, komitmen dan kepedulian personel sekolah terutama kepala sekolah dan guru terhadap permasalahan muatan lokal. Hal ini sejalan dengan hasil penelitian yang dilakukan oleh Ahmad (2014) menunjukkan bahwa "aktor utama yang dapat mempengaruhi guru adalah kepala sekolah, kepemimpinannya akan berpengaruh langsung terhadap kinerja guru, kepala sekolah bertugas selalu mengkoordinasikan kurikulum, mensupervisi dan mengevaluasi kurikulum, dan memonitor kemajuan siswa". Oleh karena itu semua personel sekolah harus memiliki paradigma yang sama agar kebijakan-kebijakan yang dibuat lebih berorientasi pada pengembangan muatan lokal yang sesuai dengan potensi dan karakteristik daerah atau dengan kata lain sesuai dengan ciri khas daerah dan dapat diimplementasikan dengan baik tanpa ada beban dan keterpaksaan.

Adapun penelitian yang dilakukan berkaitan dengan kondisi pengembangan kurikulum muatan lokal bahwa Sekolah Dasar Negeri Kota Meulaboh yang telah menerapkan Kurikulum 2013 pada pelaksanaannya melakukan pembelajaran secara tematik, namun untuk pembelajaran muatan lokal dilakukan secara berbeda dan dengan alokasi waktu serta mata pelajaran yang khusus. Berkaitan dengan pemetaan pelajaran muatan lokal yang diterapkan pada Sekolah Dasar Negeri Kota Meulaboh, yakni pelajaran bahasa Aceh, bahasa Inggris, tulisan Arab Indonesia (TAI) dan teknologi informatika (TIK). Semua Sekolah Dasar Negeri Kota Meulaboh menerapkan muatan lokal bahasa Aceh, bahasa Inggris dan TAI, serta hanya satu sekolah yang menambahkan TIK sebagai muatan lokal dapat dijabarkan pada tabel dibawah ini.

Tabel 5. Pelajaran Muatan Lokal Sekolah Dasar Negeri Negeri Kota Meulaboh

\begin{tabular}{|c|l|c|c|c|c|}
\hline \multirow{2}{*}{ No } & \multirow{2}{*}{ Nama sekolah } & \multicolumn{4}{|c|}{ Pelajaran Muatan Lokal } \\
\cline { 3 - 6 } & & B.Aceh & B.Inggris & TAI & TIK \\
\hline 1 & SDN 01 Meulaboh & $\sqrt{ }$ & $\sqrt{ }$ & $\sqrt{ }$ & $\sqrt{ }$ \\
\hline 2 & SDN 02 Meulaboh & $\sqrt{ }$ & $\sqrt{ }$ & $\sqrt{ }$ & \\
\hline 3 & SDN 03 Meulaboh & $\sqrt{ }$ & $\sqrt{ }$ & $\sqrt{ }$ & \\
\hline 4 & SDN 12 Meulaboh & $\sqrt{ }$ & $\sqrt{ }$ & $\sqrt{ }$ & \\
\hline 5 & SDN 14 Meulaboh & $\sqrt{ }$ & $\sqrt{ }$ & $\sqrt{ }$ & \\
\hline 6 & SDN 27 Meulaboh & $\sqrt{ }$ & $\sqrt{ }$ & $\sqrt{ }$ & \\
\hline
\end{tabular}

\section{KESIMPULAN}

Merujuk pada permasalahan penelitian yang telah dirumuskan, tujuan penelitian yang telah ditetapkan, dan hasil analisis yang telah dipaparkan pada bagian sebelumnya, dirumuskan kesimpulan hasil penelitian sebagai berikut. Secara umum hasil evaluasi pengembangan kurikulum muatan lokal Sekolah Dasar Negeri Kota Meulaboh secara keseluruhan menunjukkan 
bahwa sudah berkategori baik hal ini dapat ditinjau dari kondisi pengembangan kurikulum muatan lokal Sekolah Dasar Negeri Kota Meulaboh yang memperoleh persentase rata-rata berkategori baik. Pengembangan kurikulum muatan lokal didukung dengan adanya tim pengembang kurikulum sekolah.

Berkaitan dengan kondisi pengembangan kurikulum muatan lokal di Sekolah Dasar Negeri Kota Meulaboh sebaiknya perlu disusun dan dibentuk tim pengembang kurikulum muatan lokal secara khusus, hal ini didasari bahwa setiap sekolah yang menjadi responden pada penelitian ini tidak memiliki tim pengembang kurikulum muatan lokal hanya saja dalam tim pengembang kurikulum disisipkan beberapa pihak yang dianggap pantas untuk dijadikan pengembang kurikulum muatan lokal.

\section{DAFTAR PUSTAKA}

Ahmad, S. (2014). Problematika Kurikulum 2013 dan Kepemimpinan Instruksional Kepala Sekolah. Jurnal Pencerahan, 8 (2), 98-108.

Arifin, Z. (2014). Konsep Dan Model Pengembangan Kurikulum. Bandung: Remaja Rosdakarya. Arikunto, Suharsimi. (2010). Prosedur Penelitian Suatu Pendekatan Praktik. Yogyakarta: Rineka Cipta.

Hasan, H. (2009). Evaluasi Kurikulum. Bandung: Remaja Rosdakarya.

Idi, A. (2009). Pengembangan Kurikulum: Teori \& Praktik. Yogyakarta: Ar-Ruzz Media.

Kamwendo, G. \& Seretse, T. (2014). Linguistic and Religious Diversity and Inclusivity in the Botswana School Curriculum. Journal of Asian and African Studies, 50(5), 533-541.

Nasir, M. (2013). Pengembangan Kurikulum Muatan Lokal Dalam Konteks Pendidikan Islam di Madrasah. Hunafa: Jurnal Studia Islamika, 10 (1), 1-18.

Nasution, S. (2009). Asas-Asas Kurikulum. Jakarta: Bumi Aksara.

Oliva, Peter F. (1991). Developing the Curriculum. (edisi ketiga). New York. Harper Collins Publishers.

Permendikbud RI No. 79 Tahun 2014 tentang Muatan Lokal Kurikulum 2013

Qanun Aceh No. 11 Tahun 2014 Tentang Penyelenggaraan Pendidikan

Rusman. (2012). Manajemen Kurikulum. Jakarta: PT. Rajagrafindo Persada.

Sanjaya, W. (2011). Kurikulum dan Pembelajaran: Teori dan Praktik Pengembangan Kurikulum Tingkat Satuan Pendidikan (KTSP). Jakarta: Kencana Prenada Media Group.

Sugiyono. (2013). Metode Penelitian Kuantitatif Kualitatif dan R\&D. Bandung: Alfabeta.

Sukmadinata, N. S. (2014). Pengembangan Kurikulum: Teori dan Praktek. Bandung: Remaja Rosdakarya.

Suyitno, S. (2014). Sumbangsih Pembelajaran Bahasa Jawa Terhadap Pendidikan Karakter Dalam Implementasi Kurikulum 2013. Prosiding Seminar Nasional dan Bedah Buku Pendidikan Karakter dalam Implementasi Kurikulum 2013 (79-93). Semarang: Universitas PGRI Semarang.

Undang-Undang Nomor 20 Tahun 2003 Tentang Sistem Pendidikan Nasional. 